\title{
Research on the treatment effects and drug resistances of long-term second-line antiretroviral therapy among HIV-infected patients from Henan Province in China
}

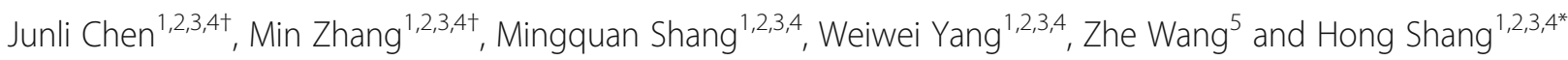

\begin{abstract}
Background: HIV/AIDS patients who fail to respond to first-line treatment protocols are switched to secondline ART. Identifying factors that influence effective second-line treatment can improve utilization of limited medical resources. We investigated the efficacy of long-term second-line anti-retroviral therapy (ART) after first-line virologic failure as well as the impact of non-nucleotide reverse transcriptase inhibitor (NNRTI), nucleotide reverse transcriptase inhibitor (NRTI), and protease inhibitor (PI) resistance mutations and medication adherence on ineffective viral suppression.

Methods: A total of 120 patients were evaluated at 6, 12, 18, 24, and 48 months after initiation of secondline ART; a paper questionnaire was administered via a face-to-face interview and venous blood samples were collected. CD4 ${ }^{+} T$ cell count, viral load, and drug resistance genotypes were quantified.

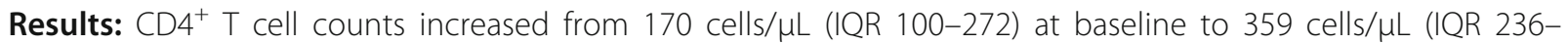
501) after 48 months of second-line treatment. Viral load $\left(\log _{10}\right)$ decreased from 4.58 copies $/ \mathrm{mL}$ (IQR 3.96-5. 17) to 1.00 copies/mL (IQR 1.00-3.15). After switching to second-line ART, nine patients newly acquired the NRTI drug-resistant mutation, M184 V/I. No major PI resistance mutations were detected. Logistical regression analysis indicated that medication adherence $<90 \%$ in the previous month was associated with ineffective viral suppression; baseline high/low/moderate level resistance to 3TC/TDF was protective towards effective viral suppression.

Conclusions: Long-term second line ART was effective in the Henan region of China. Drug resistance mutations to NRTIs were detected in patients receiving second-line ART, suggesting that drug resistance surveillance should be continued to prevent the spread of resistant strains. Patient medication adherence supervision and management should be strengthened to improve the efficacy of antiviral treatment.
\end{abstract}

Keywords: HIV-1, HAART, Second-line antiretroviral therapy, CD4 count, Viral load, Drug resistance

\footnotetext{
* Correspondence: hongshang100@hotmail.com

†Junli Chen and Min Zhang contributed equally to this work.

${ }^{1} \mathrm{NHC}$ Key Laboratory of AIDS Immunology (China Medical University), Department of Laboratory Medicine, The First Affiliated Hospital of China Medical University, No 155, Nanjing North Street, Heping District, Shenyang 110001, Liaoning Province, China

${ }^{2}$ Key Laboratory of AIDS Immunology of Liaoning Province, The First Affiliated Hospital of China Medical University, Shenyang 110001, China Full list of author information is available at the end of the article
}

(c) The Author(s). 2018 Open Access This article is distributed under the terms of the Creative Commons Attribution 4.0 International License (http://creativecommons.org/licenses/by/4.0/), which permits unrestricted use, distribution, and reproduction in any medium, provided you give appropriate credit to the original author(s) and the source, provide a link to the Creative Commons license, and indicate if changes were made. The Creative Commons Public Domain Dedication waiver (http://creativecommons.org/publicdomain/zero/1.0/) applies to the data made available in this article, unless otherwise stated. 


\section{Background}

In 2003, the "Four Free and One Care" antiretroviral therapy treatment (ART) policy was formally implemented in China [1]. This policy is comprised of 1) free antiretroviral therapy to rural patients and low-income urban patients, 2) free HIV screening and counseling, 3) free ART for pregnant women with HIV to prevent mother-to-child transmission along with free HIV testing for newborns, 4) free education for children orphaned by AIDS, and free care and economic assistance to households with members suffering from HIV/AIDS [2]. In accordance with these guidelines, the first line therapy regimen for HIV patients includes two nucleotide analogue reverse transcriptase inhibitors (NRTIs) and one non-nucleotide analogue reverse transcriptase inhibitors (NNRTIs) [3]. However, a proportion of patients who have initiated first-line ART subsequently develop drug resistance, which has been growing as the duration of ART treatment increases in China [4-7]. HIV drug resistance caused by the antiretroviral drug selection pressure is the primary reason for clinical failure of ART. In 2009, patients with failure of the first-line treatment protocol have switched to second-line ART, which is comprised of 3TC (lamivudine), TDF (Tenofovir), and Lpv/r (Lopinavir/ritonavir). More than 55,000 patients have received second line ART in China as of 2016 [8].

Although second-line treatment regimens include two NRTIs, 3TC and TDF, multidrug resistance and cross-resistance mutations acquired during first-line ART often results in only partial effectiveness of the NRTIs during second-line treatment. Some small sample size studies conducted in China have reported an increase in $\mathrm{CD}^{+} \mathrm{T}$ cells in HIV-infected patients within 12 months of the switch to second-line treatment; HIV viral loads were lower than at the time of first-line failure in these patients as well [9-11]. Ding et al's found that viral suppression rates reached $96.3 \%$ (viral load < 400 copies $/ \mathrm{ml}$ ) and $\mathrm{CD} 4^{+} \mathrm{T}$ cell counts were 531 after 36 months of second-line ART in patients from northeast China [12]. However, medical resources are unequal among different regions and AIDS-treatment institutions in China [13]; thus, long-term studies of the effectiveness of second-line treatment are still necessary in China. Investigation of the efficacy of second-line ART in resource-limited countries has revealed an increase in viral suppression and $\mathrm{CD}^{+} \mathrm{T}$ cell counts within 24 months of switching to second-line therapy [14-17]. The EARNEST trial in sub-Saharan African countries showed that antiviral therapy was effective during the long-term second-line therapy [18]. However, viral subtypes and composition of the first-line protocol often differ between China and other countries. Thus, long-term observational study of second-line treatment efficacy in China is needed.
Drug selection pressure caused by the therapy regimen changes can lead to the accumulation of drug resistance mutations during long-term treatment. An increase in NRTI drug resistance was reported in patients after switching to the second line regimen [19]. Protease inhibitors (PI) such as Lpv/r (Lopinavir/ritonavir) replace NNRTIs in second-line regimens as it has been reported that mutations resulting in lopinavir resistance are infrequent [20-22]. However, Olawale Ajose et al. reported that PI resistance mutations were found in $18 \%$ of patients as determined via HIV genotyping [23]. In order to effectively guide treatment, it is essential to know whether different resistance mutations appear during long term second-line ART.

Here, we describe a prospective study of a cohort of patients with AIDS within 4 years of initiation of second-line treatment in Weishi County of Henan Province in China. We examined both the effectiveness of second-line treatment as well as associated factors which can impact treatment; importantly, we also analyzed whether cumulative NRTI resistance mutations acquired during first-line therapy failure affected the efficacy of second-line therapy. We also analyzed changes in PI, NRTI, and NNRTI resistance mutations after long-term second-line therapy.

\section{Methods}

\section{Ethics statement}

This research was approved by the Institutional Review Board of the first Affiliated Hospital of China Medical University. All participants signed informed consent statements.

\section{Study population}

Patients were recruited from Henan between August 2009 and February 2010. Inclusion criteria were those listed in the Chinese National Free AIDS Antiretroviral Therapy Manual issued in 2009 [24] and in the WHO guidelines for antiretroviral therapy for HIV infection in adults and adolescents [25]: (1) $\geq 18$ years of age; (2) virologic failure of first-line therapy, defined as a plasma HIV-1 RNA level $>400$ copies $/ \mathrm{mL}$ after 6 months of treatment or an HIV-1 RNA level $>1000$ copies $/ \mathrm{mL}$ after initial virologic suppression; (3) virologic treatment failure confirmed: viral load $>1000$ copies $/ \mathrm{mL}$ after patients resumed first-line treatment for one month with rectified treatment compliance; (4) second-line therapy protocol including lamivudine (3TC), tenofovir (TDF), and lopinavir/ritonavir (LPV/r) as the second-line antiretroviral regimen; and (5) at least one follow-up visit after the switch to the second-line antiretroviral therapy regimen.

After 6, 12, 18, 24, and 48 months of second-line therapy, we administered a paper questionnaire 
through a face-to-face interview and collected blood samples to assess patients' $\mathrm{CD}^{+}{ }^{+} \mathrm{T}$ cell count, HIV viral load, and "in-house" HIV genotype drug resistance test. During second-line therapy, "ineffective viral suppression" is defined as follows: plasma HIV-1 RNA level $>1000$ copies/mL after 12 months of treatment; viral rebound which is defined as plasma HIV-1 RNA level $>1000$ copies/mL after initial virologic suppression during second-line ART.

\section{Data acquisition}

$\mathrm{CD}^{+}$T lymphocyte count: a FACSCalibur flow cytometer (Becton Dickinson, USA) was used to enumerate $\mathrm{CD} 4^{+}$, $\mathrm{CD}^{+}$, and $\mathrm{CD}^{+} \mathrm{T}$ lymphocytes. Peripheral venous blood was collected and treated with EDTA-3 K anticoagulant; $\mathrm{T}$ lymphocyte counts were obtained within $24 \mathrm{~h}$.

Viral load: Plasma obtained from patients' venous blood samples was stored at $-80{ }^{\circ} \mathrm{C}$ until testing. HIV viral load was determined using a COBAS AmpliPrep/ COBAS TaqMan HIV-1 test (Roche, Switzerland). The detection range of the COBAS Assay for viral load quantification is $20-10^{7}$ copies $/ \mathrm{mL}$.

Drug-resistant mutation analysis: Mutations in the HIV polymerase gene, Pol, were screened for drug resistance mutations. $H I V-1$ viral RNA was extracted from $200 \mu \mathrm{l}$ plasma with a QIAamp Viral RNA Mini Kit (Qiagen, Germany). One-step Reverse transcription-polymerase chain reaction (RT-PCR) was carried out using a TaKaRa One-step RNA PCR Kit (Takara Bio, China). The HIV-1 pol gene was amplified using first round primers MAW26 (5'-TTGGAAATGTGGAAAGGAAGGAC-3'; HXB2 2028-2050) and RT21 (5'-CTGTATTTCTGCTATTAAG TCTTTTGATGGG-3'; HXB2 3509-3539); amplification was achieved using 1 cycle of $50^{\circ} \mathrm{C}$ for $30 \mathrm{~min}, 1$ cycle of $94{ }^{\circ} \mathrm{C}$ for $5 \mathrm{~min}$, and 30 cycles of $94{ }^{\circ} \mathrm{C}$ for $30 \mathrm{~s}, 55^{\circ} \mathrm{C}$ for $30 \mathrm{~s}$, and $72{ }^{\circ} \mathrm{C}$ for $2 \min 30 \mathrm{~s}$, with a final extension of $72^{\circ}$ $\mathrm{C}$ for $10 \mathrm{~min}$ in the first round; and second round primers PRO-1 (5'-CAGAGCCAACAGCCCCACCA-3'; HXB2 3509-3539) and RT4R (5'-CTTCTGTATATCATTGACA GTCCAGCT-3'; HXB2 3509-3539);amplification was achieved using 1 cycle of $94{ }^{\circ} \mathrm{C}$ for 5 min and 30 cycles of $94{ }^{\circ} \mathrm{C}$ for $30 \mathrm{~s}, 63^{\circ} \mathrm{C}$ for $30 \mathrm{~s}$, and $72{ }^{\circ} \mathrm{C}$ for $2 \mathrm{~min} 30 \mathrm{~s}$, with a final extension of $72^{\circ} \mathrm{Cfor} 10 \mathrm{~min}[11,26]$. Positive, negative, and blank controls were included for PCR quality control; positive control: HIV-positive specimens and containing the pol gene; negative control: specimens that are HIV-negative; blank control: amplification without template. The negative and positive controls were extracted, amplified, detected, and analyzed simultaneously with the research sample. Sequences were aligned using Contig software and edited using Bioedit software. The resulting sequences were submitted to the Stanford University HIV drug resistance database (http://hivdb.stanford.edu) for interpretation of putative drug resistance results.

\section{Statistical analysis}

SPSS software (version 17.0) was used to analyze quantitative data. Categorical data was described by rate or ratio and analyzed by either Chi-square test or Fisher's exact test. Continuous data was described by the mean and standard deviation if data met the hypothesis of normal distribution, otherwise median and inter-quartile ranges (IQRs) were used. Univariate and multivariate logistic regression were performed to identify possible associated factors that may have contributed to viral suppression. $P<0.05$ for two-sided tests was defined as statistically significant.

\section{Results}

Baseline information for HIV-infected patients undergoing long-term second-line antiretroviral therapy

Of the 120 patients that met the inclusion criteria for second-line therapy in our cohort, the median age was $45.2(39.8-52.3)$ years, $60.8 \%(73 / 120)$ were male, $39.2 \%$ were female (47/120). 95.8\% (115/120) of patients were infected through paid blood donation(blood transfusion). All HIV Pol sequences were subtype B interpreted by the Stanford University HIV drug resistance database. All 120 patients used first-line therapy regimens (2NRTIs + 1NNRTIs); first-line treatment duration was 5.0 (3.7-5.5) (median, IQR) years. At initiation of second-line therapy, patient baseline viral load (lg10) (median, IQR) and mean $\mathrm{CD} 4^{+} \mathrm{T}$ cell count (median, IQR) were $4.58(3.96-5.17)$ copies $/ \mathrm{ml}$ and $170(100-$ 272) cells $/ \mu$ l, respectively. After first-line failure, drug resistance rates to 3TC and TDF were $32.5 \%(38 / 117)$ and $48.7 \%$ (57/117), respectively (Table 1 ). None of the patients exhibited resistance to $\mathrm{LPV} / \mathrm{r}$.

\section{Efficacy of long-term second-line antiretroviral treatment}

Staff members regularly followed up with patients. After switching to second-line treatment, 102, 104, 82, 90, and 85 patients were retained for follow-up at $6,12,18,24$, and 48 months, respectively. Of the 16 patients who were lost to follow-up at 6 months, two continued second-line therapy according to drug receipt records from the CDC; however, we were unable to collect blood samples and therapy records from these two patients as they were away from Weishi county, Henan province at 6 months. We were able to retrieve blood samples and therapy information from these patients at 12 month. The number of patients who were lost to follow-up increased to 30 at 18 months; Another eight patients continued second-line therapy according to drug receipt records from the $\mathrm{CDC}$; however, we were unable to collect blood samples and therapy records from these patients as they were away from Weishi county at the 18 month timepoint. We were able to obtain their blood samples and therapy information at the 24 month 
Table 1 Baseline information before second-line antiretroviral treatment

\begin{tabular}{|c|c|c|}
\hline Variable & Category & Numerical value \\
\hline \multirow[t]{2}{*}{ Gender (n. \%) } & Male & $73(60.8 \%)$ \\
\hline & Female & $47(39.2 \%)$ \\
\hline Age (years, IQR) & & $45.2(39.8-52.3)$ \\
\hline \multirow[t]{3}{*}{ Education degree $(n, \%)$} & Primary school & $61(50.8 \%)$ \\
\hline & Junior middle school & $40(33.3 \%)$ \\
\hline & Illiteracy & 19(15.8\%) \\
\hline Occupation (n, \%) & Farmer & $120(100 \%)$ \\
\hline \multirow[t]{4}{*}{ Route of infection (n, \%) } & $\begin{array}{l}\text { Paid blood } \\
\text { donation(blood } \\
\text { transfusion) }\end{array}$ & 115(95.8\%) \\
\hline & Heterosexual & $3(2.5 \%)$ \\
\hline & Blood transfusion & $1(0.8 \%)$ \\
\hline & Unknown & $1(0.8 \%)$ \\
\hline $\begin{array}{l}\text { Duration of first-line treat- } \\
\text { ment (years, IQR) }\end{array}$ & & $5.0(3.7-5.5)$ \\
\hline \multirow[t]{3}{*}{ NRTIs drug resistance $(n, \%)$} & & $68(58.1 \%)$ \\
\hline & 3TC drug resistance & $38(32.5 \%)$ \\
\hline & TDF drug resistance & $57(48.7 \%)$ \\
\hline NNRTIs drug resistance $(\mathrm{n}, \%)$ & & $84(71.8 \%)$ \\
\hline Lpv/r drug resistance $(n, \%)$ & & $0(0)$ \\
\hline $\begin{array}{l}\text { Baseline viral load (lg10) } \\
\text { (median, IQR) copies/ml }\end{array}$ & & $4.58(3.96-5.17)$ \\
\hline $\begin{array}{l}\text { Baseline CD4 + T cells } \\
\text { (median, IQR) cells/ } / \mu l\end{array}$ & & $170(100-272)$ \\
\hline
\end{tabular}

3TC Lamivudine, TDF Tenofovir, NRT/s Nucleoside reverse transcriptase inhibitor, NNRT/s Non-nucleoside reverse transcriptase inhibitor, Lpv/r Lopinavir/ritonavir

timepoint. Finally, 35 patients were lost to follow-up at 48 months.

During long-term second-line therapy, patients' $\mathrm{CD} 4^{+}$ $\mathrm{T}$ cells increased from a baseline of 170 cells/ $\mu \mathrm{L}$ (IQR 100-272) at initiation of second-line therapy to 359 cells/ $\mu \mathrm{L}$ (IQR 236-501) after 48 months of treatment, which was statistically significant $(P<0.05)$ (Table 2 ). The proportion of patients whose $\mathrm{CD} 4^{+} \mathrm{T}$ cells counts were $>350$ cells $/ \mu \mathrm{L}$ at baseline, $6,12,18,24$, and 48 months after initiation of second-line treatment increased (trend test chi-square value $=52.3,<0.001$ ) .
Viral load $\left(\log _{10}\right)$ decreased from an average baseline level of 4.58 copies/mL (IQR 3.96-5.17) to 1.00 copies/ $\mathrm{mL}$ (IQR 1.00-3.15) after 48 months of second-line therapy. HIV viral load decreased significantly $(\mathrm{P}<0.05)$ after several different durations of second-line treatment (Table 2). The proportion of patients whose viral load was $<1000$ copies $/ \mathrm{mL}$ increased with time of second-line treatment (trend test chi-square value $=108.0, P<0.001$ ). The proportion of patients with viral loads $<1000$ copies $/ \mathrm{mL}$ at $6,12,18,24$, and 48 months was $61.8 \%(63 /$ 102), $71.1 \%$ (74/104), $69.5 \%$ (57/82), $70.0 \%$ (63/90), and $75.3 \%(64 / 85)$, respectively. The proportion and frequency of patients with $<50 \mathrm{HIV}$-RNA copies/mL at 6 , $12,18,24$ and 48 months was $43.1 \%$ (44/102), 43.4\% (45/104), 42.7\% (35/82), 50\% (45/90), and 67.1\% (57/85), respectively.

\section{$\mathrm{PI} / \mathrm{NRTI} / \mathrm{NNRTI}$ drug resistance mutations among patients with virologic treatment failure during second-line treatment}

In-house genotype drug resistance tests were performed on samples from patients whose viral loads were $>1000$ copies/ml. All sequences obtained during second-line treatment were HIV subtype B as interpreted by the Stanford University HIV drug resistance database. Rates of drug resistance to NRTIs were $58.1 \%$ (68/117), $43.3 \%$ (13/30), 31.8\% (7/22), 28.0\% (7/25), 18.1\% (2/11), 31.6\% (6/19) at baseline, $6,12,18,24$, and 48 months, respectively. Rates of drug resistance rates to NNRTIs were $71.8 \%$ (84/117), $56.7 \%$ (17/30), $45.5 \%$ (10/22), $24.0 \%$ (6/ 25), 36.3\% (4/11), and 36.8\% (7/19) at baseline, $6,12,18$, 24 , and 48 months, respectively. No major resistance to PIs was detected in our study; minor drug resistance to the PIs, A71V/T and L10I, were detected during second-line therapy.

After switching to second line ART, newly acquired NRTIs resistance mutations at position 184, which are associated with resistance to 3TC, were detected in nine HIV/AIDS patients. The M184 V/I mutation was detected in five patients, one patient, two patients, and one patient at the $6,12,18$, and 48 month timepoints, respectively. Mutation K65R, associated with resistance to TDF, was found in four patients at baseline; however,

Table 2 Results of CD4 + T cells and viral load within the 48 months second-line antiretroviral treatment

\begin{tabular}{llllll}
\hline $\begin{array}{l}\text { Duration of treatment } \\
\text { (month) }\end{array}$ & $\begin{array}{l}\text { Patients } \\
\text { followed-up (n) }\end{array}$ & $\begin{array}{l}\text { Viral load (Ig10) (median, } \\
\text { IQR) copies/ml }\end{array}$ & $\begin{array}{l}\text { Viral load compared } \\
\text { with baseline }\end{array}$ & $\begin{array}{l}\text { CD4 + cells (median, } \\
\text { IQR) cells/ } \mu \text { l }\end{array}$ & $\begin{array}{l}\text { CD4 compared with } \\
\text { baseline }\end{array}$ \\
\hline Baseline & 120 & $4.58(3.96-5.17)$ & - & $170(100-272)$ & - \\
6 & 102 & $2.02(1.00-3.84)$ & $P<0.001$ & $230(164-323)$ & $P<0.001$ \\
12 & 104 & $1.60(1.00-3.38)$ & $P<0.001$ & $246(185-349)$ & $P<0.001$ \\
18 & 82 & $1.77(1.00-3.87)$ & $P<0.001$ & $296(186-394)$ & $P<0.001$ \\
24 & 90 & $1.70(1.00-3.90)$ & $P<0.001$ & $316(205-436)$ & $P<0.001$ \\
48 & 85 & $1.00(1.00-3.15)$ & $P<0.001$ & $359(236-501)$ & $P<0.001$ \\
\hline
\end{tabular}


after switching to second-line ART, K65R mutations were not detected. TAM (M41 L, K70R, L210 W, and $\mathrm{T} 215 \mathrm{~F}$ ) and $\mathrm{D} 67 \mathrm{~N}$ mutations, associated with resistance to TDF, were detected during second-line ART. NRTI drug-resistance mutations were not found in some patients from the baseline point to 48 months after beginning second-line treatment (NRTIs resistance mutations are shown in Table 3). Mutations at position 103, 106, and 190 are associated with resistance to NNRTIs and were detected during treatment (Table 4).

\section{Analysis of factors associated with ineffective viral suppression}

At least 12 months after switching to the second-line regimen, we identified 31 patients whose viral load had rebounded; 28 of which whose viral load was $>1000$ copies/ml. Logistical regression analysis was used to identify factors associated with ineffective viral suppression. The results were as follows: 1) medication adherence (the past month) below 90\% (vs. 90-100\%) (aOR $=22.74$, 95\%CI: 3.38-152.59); 2) compliance unknown (vs. 90$100 \%)(\mathrm{aOR}=9.40,95 \% \mathrm{CI}: 2.98-29.67)$, these two factors were protective toward ineffective viral suppression. 3) baseline high level resistance to 3TC/TDF (vs. sensitive) $(\mathrm{aOR}=0.10,95 \% \mathrm{CI}: 0.24-0.43)$; and 4) baseline low/moderate level resistance to 3TC/TDF (vs sensitive) $(\mathrm{aOR}=0.29,95 \% \mathrm{CI}: 0.10-0.83)$ (Table 5), the two factors were protective toward effective viral suppression.

\section{Discussion}

In our study, patients were recruited from Henan province in China; Henan was one of the earliest areas to begin free first-line ART for HIV-infected citizens and was the first to initiate second-line antiretroviral therapy as described in the National Free Antiretroviral Treatment Program (NFATP). During the 4 years of follow-up, patient $\mathrm{CD} 4^{+} \mathrm{T}$ cell counts were significantly higher than at baseline and viral load was significantly lower. The median $\mathrm{CD} 4^{+} \mathrm{T}$ counts increased by an average of 146 cells/L and 70\% (63/ 90) of patients achieved viral suppression within 24 months in our study, which was similar to results reported from South Africa in which $\mathrm{CD} 4^{+} \mathrm{T}$ counts increased by an average of 177 cells/L and 75\% (74/99) of patients achieved a viral load $<1000$ copies $/ \mathrm{mL}$ within 24 months of beginning second line therapy [27]. We also analyzed the efficacy of 48 months of second-line therapy; $\mathrm{CD} 4^{+} \mathrm{T}$ counts increased to 189 cells/L and $75.3 \%(64 / 85)$ of patients achieved a viral load $<1000$ copies $/ \mathrm{mL}$. These results indicate that long-term treatment was effective in our cohort.

Drug-resistance mutations were detected when the viral load reached > 1000 copies/ml during second-line ART follow-up; yet, our results show that newly acquired NRTI resistance mutations were few. The M184 V/I mutation was detected in nine patients after switching to second-line therapy, which can attributed to the use of 3TC in the program. Boyd et al. found that one patient newly acquired M184 V resistance mutations after 96 weeks second-line ART [22]. TDF was used in the second-line program; the mutations associated with resistance to TDF were K65R, TAM (M41 L, K70R, L210 W, T215F), D67N, K70E, and Y115F. The K65R mutation causes intermediate/high-level resistance to TDF; use of TAMs (M41 L, K70R, L210 W, T215F) can reduce TDF susceptibility and cause intermediate/low level resistance to TDF. The D67N mutation, present with other TAMs, can result in reduced susceptibility to TDF. The K70E and Y115F mutations cause low-level resistance to TDF as well $[28,29]$. In our study, K65R was detected in four patients at baseline, which may be related to drugs used in the first-line ART; these four patients achieved viral suppression during second-line treatment. However, K65R was not detected in other patients after switching to second-line ART, which was consistent with Boyd et al. [22]. TAM resistance mutations did not accumulate significantly in our study, but the results from Reynolds et al. show that TAM (M41 L, L210 W, and T215F/Y) and M184I/V mutations related to NRTI drug resistance increased after patients switched to the second-line regimen [19]. These inconsistent results may be due to different first-line treatment regimens, different HIV subtypes, or the differences in patients' drug metabolism or medication adherence.

Major PI resistance mutations were not detected using the "in-house" genotype drug resistance test. However, we obtained HIV Pol sequences using monoclonal methods; the results of a rootless radial tree generated via phylogenetic analysis at the two time points (baseline and after 48 months of second-line treatment) showed significant evidence of viral evolution, suggesting that resistance surveillance should be continued.

After switching to the second-line regimen, 31 patients exhibited increased viral load; of these, 28 patients exhibited viral loads $>1000$ copies $/ \mathrm{ml}$ after at least 12 months of second-line therapy. We performed a logistical regression analysis of the data; our results indicated that medication adherence (in the past month) below 90\%, compliance or when medication adherence was unknown was associated with ineffective viral suppression. These results are consistent with the work reported by Murphy et al. [27]. In a study conducted in India, Khan et al. reported $62 \%$ of patients with failure of second-line therapy had a subsequently undetectable viral load after a median duration of 3 months if they remained on second-line ART after enhanced adherence support [30]. Taken together, these data suggest that more effective measures are needed to improve patient medication adherence and thus improve utilization of the limited medical resources. 


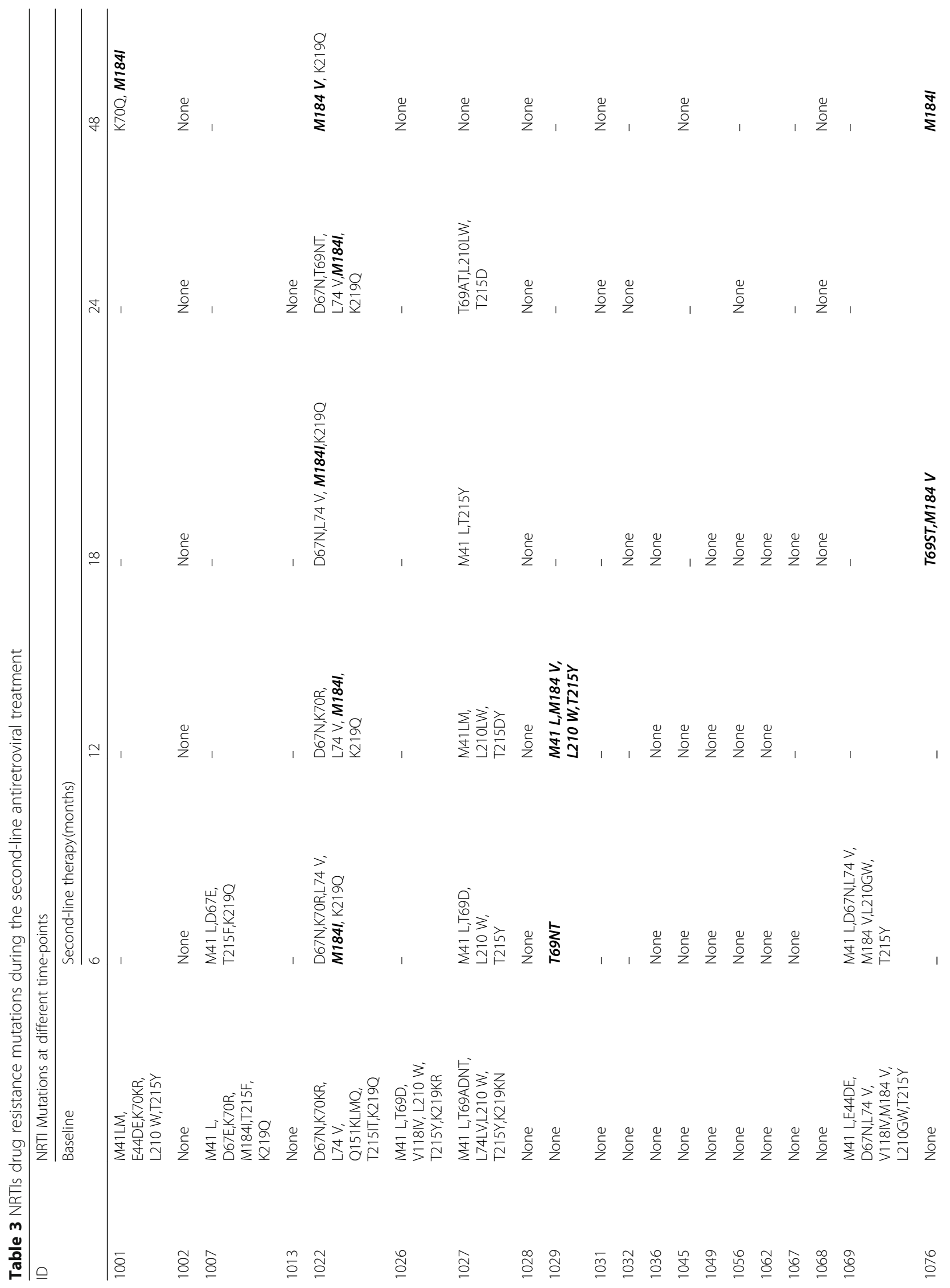




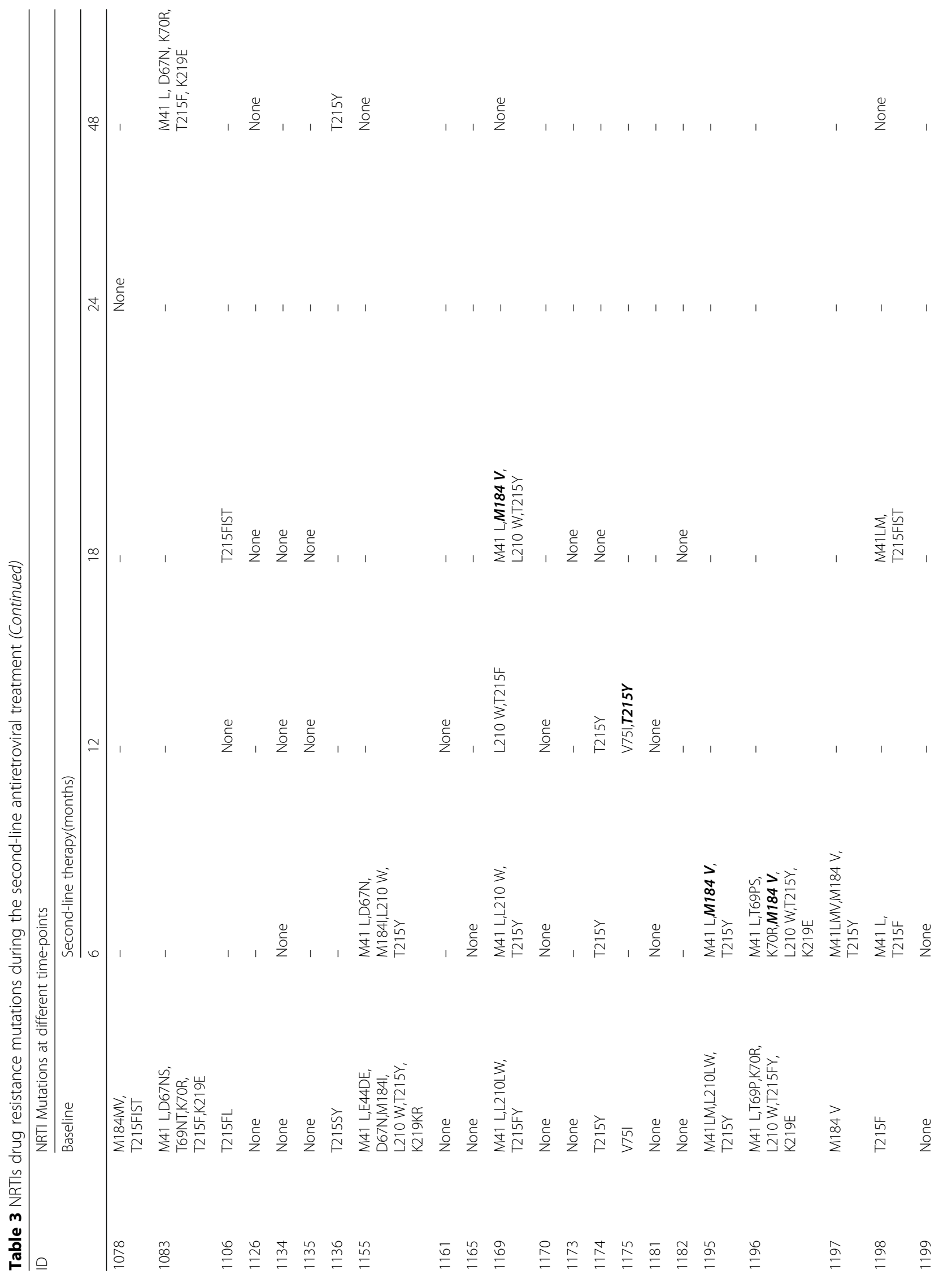




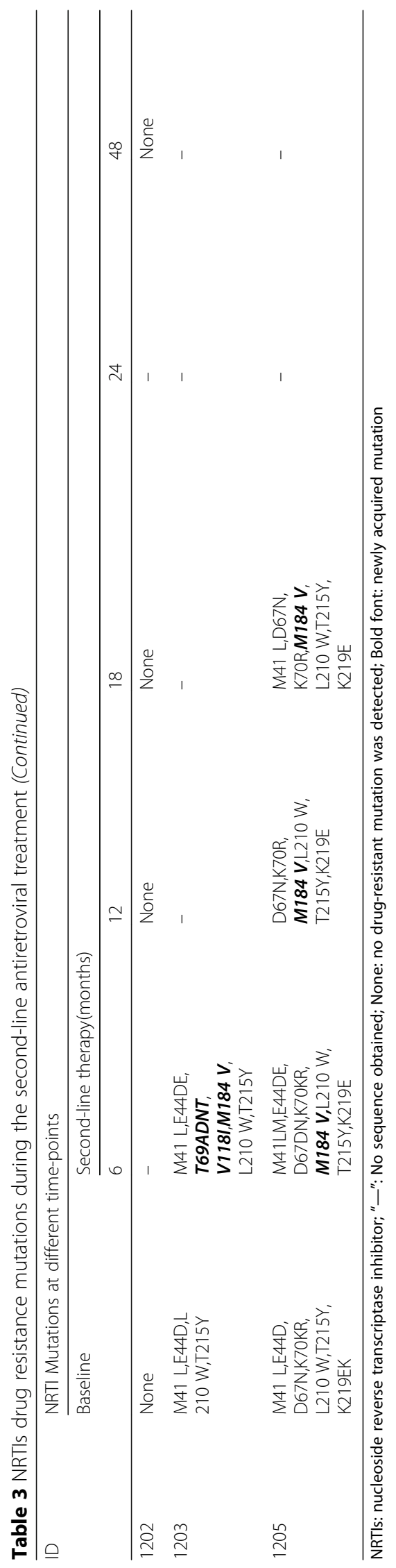


Table 4 NNRTIs drug resistance mutations during the second-line antiretroviral treatment

\begin{tabular}{|c|c|c|c|c|c|c|}
\hline \multirow[t]{3}{*}{ ID } & \multicolumn{6}{|c|}{ NNRTI Mutations at different time-points } \\
\hline & \multirow[t]{2}{*}{ Baseline } & \multicolumn{5}{|l|}{ Second-line therapy(months) } \\
\hline & & 6 & 12 & 18 & 24 & 48 \\
\hline 1001 & V106AV,Y181C,H221Y & - & - & - & - & K103 N \\
\hline 1002 & None & None & None & None & None & None \\
\hline 1007 & K103 N,Y181C & K103 N,Y181C & - & - & - & - \\
\hline 1013 & K103 N & - & - & - & K103 N & \\
\hline 1022 & V90I,K103S,G190A & V90I,K103S,G190A & K103S,G190A & K103S,G190A & K103S,G190A & V90I, K103S, G190A \\
\hline 1026 & V106A,V108I,F227 L & - & - & - & - & None \\
\hline 1027 & V108I,Y181C,H221Y & V108I,Y181C,H221Y & V108I,Y181C & V108I,Y181C & V108I,Y181C & V108I, Y181CY \\
\hline 1028 & None & None & None & None & None & None \\
\hline 1029 & Y181C,H221HY & V106A,F227 L & & & & \\
\hline 1031 & K103 N & - & - & - & K103 N & - \\
\hline 1032 & $\mathrm{H} 221 \mathrm{Y}$ & - & - & None & None & - \\
\hline 1036 & None & V179DV & & & & \\
\hline 1045 & K103 N,P225HY,F227FL & K103 N,P225HPSY,F227FL & K103 N,P225HP,F227FL & & & K103 N \\
\hline 1049 & None & None & None & None & & \\
\hline 1056 & None & None & None & None & None & - \\
\hline 1062 & None & None & None & None & & \\
\hline 1067 & None & None & - & None & - & - \\
\hline 1068 & K103KN & & & None & None & None \\
\hline 1069 & K103 N,Y181C,K238H & $\mathrm{K} 103 \mathrm{~N}, \mathrm{Y} 181 \mathrm{C}, \mathrm{K} 238 \mathrm{H}$ & - & - & - & - \\
\hline 1076 & None & & & None & None & None \\
\hline 1078 & K101KPQT,K103KN & - & - & - & None & - \\
\hline 1083 & Y188L & - & - & - & - & Y188L \\
\hline 1106 & V179IL,Y188FHLY & - & None & Y188FHLY & - & - \\
\hline 1112 & None & V106IV,G190S & & & & \\
\hline 1126 & None & - & - & None & - & - \\
\hline 1134 & None & None & None & None & & \\
\hline 1135 & K103KN & - & K103 N & None & - & - \\
\hline 1136 & $\mathrm{~K} 103 \mathrm{~S}, \mathrm{G} 190 \mathrm{~A}, \mathrm{H} 221 \mathrm{HY}$ & - & - & - & - & K103S, G190A \\
\hline 1155 & K101E,G190S & K101E,G190S & - & - & - & None \\
\hline 1161 & K103 N,Y181C,H221Y & - & K103 N,Y181C & - & - & - \\
\hline 1165 & None & None & - & - & - & - \\
\hline 1169 & K101HKNQ,K103KN,G190A & $\mathrm{K} 101 \mathrm{H}, \mathrm{G} 190 \mathrm{~A}$ & K101H,G190A & $\mathrm{K} 101 \mathrm{H}, \mathrm{G} 190 \mathrm{~A}$ & - & None \\
\hline 1170 & None & None & None & - & - & - \\
\hline 1173 & None & - & - & None & - & - \\
\hline 1174 & V106I,V108I,G190A & V106I,V108I,G190A & V108I,G190A & None & - & - \\
\hline 1175 & K103 N & - & K103 N & - & - & - \\
\hline 1181 & None & None & None & - & - & - \\
\hline 1182 & G190S & - & - & None & - & - \\
\hline 1195 & K103 N,V108I,P225H,K238 T & K103 N,V108I,P225H,K238 T & - & - & - & - \\
\hline 1196 & V106A,F227Y,M230 L & V106A,F227Y,M230 L & - & - & - & - \\
\hline 1197 & $\mathrm{~K} 101 \mathrm{HN}, \mathrm{V} 108 \mathrm{l}, \mathrm{Y} 181 \mathrm{C}, \mathrm{H} 221 \mathrm{Y}$ & $\mathrm{K} 101 \mathrm{HN}, \mathrm{V} 108 \mathrm{I}, \mathrm{Y} 181 \mathrm{C}, \mathrm{H} 221 \mathrm{Y}$ & - & - & - & - \\
\hline 1198 & Y188L & V90I,Y188L & & Y188FLY & & V106IV \\
\hline
\end{tabular}


Table 4 NNRTIs drug resistance mutations during the second-line antiretroviral treatment (Continued)

\begin{tabular}{|c|c|c|c|c|c|c|}
\hline \multirow[t]{3}{*}{ ID } & \multicolumn{6}{|c|}{ NNRTI Mutations at different time-points } \\
\hline & \multirow[t]{2}{*}{ Baseline } & \multicolumn{5}{|c|}{ Second-line therapy(months) } \\
\hline & & 6 & 12 & 18 & 24 & 48 \\
\hline 1199 & None & - & - & - & - & None \\
\hline 1202 & None & - & None & None & - & None \\
\hline 1203 & K103 N,Y181C & K103 N,Y181C & - & - & - & - \\
\hline 1205 & V106 M,Y188C & V106 M,Y188CFLR & V106 M,Y188L & V106 M,Y188L & - & - \\
\hline
\end{tabular}

NNRTIs Non-nucleoside reverse transcriptase inhibitor; "-":No sequence obtained; None: no drug-resistant mutation was detected;

In our cohort, baseline resistance to $3 \mathrm{TC} / \mathrm{TDF}$ resulted from ineffectiveness of the second-line ART; which was similar to the research reported regarding second line treatment in Africa [15, 31]. Paton et al. also found that greater sensitivity to NRTI was associated with poorer viral load suppression; they suggest that NRTI activity in protease inhibitor-based second-line ART was not accurately predicted by the results of genotypic resistance [17]. Some reports indicate that the NRTI resistance mutation, M184 V, can enhance viral sensitivity to TDF [32], which could result in effective virus suppression. We suspect mutations in the reverse transcriptase inhibitor and protease inhibitor regions act synergistically to enhance the virus sensitivity to the PIs; however, this will require further verification. Some researchers have other opinions, as Hosseinipour et al. suggested that first-line treatment failure in patients with wild HIV strains indicates poor medication adherence [15]. Therefore, we also need to compare the second-line treatment results between the baseline NRTI-resistant and baseline NRTI-sensitive patients under conditions of good medication adherence in future.

\section{Conclusions}

Long-term second-line antiviral therapy in the Henan region was effective. During the four years of second-line therapy, drug mutations conferring resistance to NRTIs were observed among patients receiving

Table 5 Univariate and multivariate analyzes the factors associated with ineffective viral suppression

\begin{tabular}{|c|c|c|c|c|c|}
\hline Predictor & & $\mathrm{OR}(95 \% \mathrm{Cl})$ & $p$ & a $\mathrm{OR}(95 \% \mathrm{Cl})$ & $p$ \\
\hline \multirow[t]{2}{*}{ Age(years) } & $\leq 45$ & 1 & & & \\
\hline & $>45$ & $0.72(0.35,1.48)$ & 0.367 & & \\
\hline \multirow[t]{2}{*}{ Gender } & Male & 1 & & & \\
\hline & Female & $0.74(0.36,1.55)$ & 0.431 & & \\
\hline \multirow[t]{3}{*}{ Education degree } & illiteracy & 1 & & & \\
\hline & Primary school & $1.23(0.44,3.44)$ & 0.699 & & \\
\hline & Junior middle school & $0.91(0.30,2.72)$ & 0.865 & & \\
\hline \multirow[t]{3}{*}{ Baseline CD4 + T cells/ $\mu \mathrm{l}$} & $\mathrm{CD} 4 \leq 50$ & $2.86(0.64,12.7)$ & 0.168 & $2.68(0.35,20.35)$ & 0.340 \\
\hline & $50<\mathrm{CD} 4 \leq 200$ & $1.63(0.77,3,47)$ & 0.202 & $1.20(0.45,3.19)$ & 0.450 \\
\hline & CD4 > 200 & 1 & & & \\
\hline \multirow[t]{3}{*}{ Baseline viral load copies/ml } & $1000<$ HIV RNA $\leq 10,000$ & 1 & & 1 & \\
\hline & $10,000<$ HIV RNA $\leq 10,000$ & $1.31(0.52,3.31)$ & 0.567 & $1.07(0.34,3.32)$ & 0.914 \\
\hline & HIV RNA > 100,000 & $3.46(1.27,9.37)$ & 0.015 & $2.18(0.63,7.61)$ & 0.221 \\
\hline \multirow[t]{2}{*}{ Duration of first-line therapy (years) } & $\leq 4$ & 1 & & & \\
\hline & $>4$ & $1.35(0.60,3.04)$ & 0.475 & & \\
\hline \multirow[t]{3}{*}{ Baseline 3TC/TDF resistance } & sensitive & 1 & & 1 & \\
\hline & low/moderate resistance & $0.28(0.12,0.66)$ & 0.004 & $0.29(0.10,0.83)$ & 0.022 \\
\hline & high resistance & $0.16(0.05,0.49)$ & 0.001 & $0.10(0.24,0.43)$ & 0.002 \\
\hline \multirow[t]{3}{*}{ medication adherence } & $90-100 \%$ & 1 & & 1 & \\
\hline & $<90 \%$ & $9.98(2.00,49.89)$ & 0.005 & $22.74(3.38,152.59)$ & 0.001 \\
\hline & unknown & $7.48(2.95,18.97)$ & $<0.001$ & $9.40(2.98,29.67)$ & $<0.001$ \\
\hline
\end{tabular}


second-line ART, although major drug resistance mutations were not detected in the PI region. Drug resistance monitoring should be continued to prevent the spread of resistant strains. In addition, medication adherence supervision and management should be increased in order to improve the effectiveness of antiviral drugs.

\section{Abbreviations}

3TC: Lamivudine; AIDS: Acquired immunodeficiency syndrome; ART: Antiretroviral therapy; HIV: Human immunodeficiency virus; Lpv/r: Lopinavir/ ritonavir; NNRTI: Non-nucleotide reverse transcriptase inhibitor; NRTI: Nucleotide reverse transcriptase inhibitor; PI: Protease inhibitor; TAM: thymidine analogue mutation; TDF: Tenofovir

\section{Acknowledgments}

We thank Serena Fuller and Wen Xiaoning of USCDC GAP for comments and suggestions, and Professor Ping Zhong of Shanghai CDC for helping to improve the presentation of the paper.

\section{Funding}

This study was supported by the Twelfth Five-Year Project on Tackling Key Problems of National Science and Technology (2012ZX10001002002-013) and the National Natural Science Foundation of China (81171619).

\section{Availability of data and materials}

All original data analyzed during this study are not yet publicly available as the patients are still undergoing follow up and data analysis of the cohort has not been completed. Reasonable requests for data can be made by contacting the first authors and corresponding author.

\section{Authors' contributions}

JLC, MZ, ZW and HS designed the experiments. JLC, MZ, MQS, and WWY performed the experiments. JLC, MZ, MQS, and WWY analyzed the data. JLC and $M Z$ contributed to the writing of the manuscript. All authors read and approved the final manuscript.

\section{Ethics approval and consent to participate}

This research was approved by the Ethics Committee of the first Affiliated Hospital of China Medical University. All participants signed informed consent statements.

\section{Consent for publication}

Not applicable.

\section{Competing interests}

The authors declare that they have no competing interests.

\section{Publisher's Note}

Springer Nature remains neutral with regard to jurisdictional claims in published maps and institutional affiliations.

\footnotetext{
Author details

${ }^{1} \mathrm{NHC}$ Key Laboratory of AIDS Immunology (China Medical University), Department of Laboratory Medicine, The First Affiliated Hospital of China Medical University, No 155, Nanjing North Street, Heping District, Shenyang 110001, Liaoning Province, China. ${ }^{2}$ Key Laboratory of AIDS Immunology of Liaoning Province, The First Affiliated Hospital of China Medical University, Shenyang 110001, China. ${ }^{3}$ Key Laboratory of AIDS Immunology, Chinese Academy of Medical Sciences, Shenyang 110001, China. ${ }^{4}$ Collaborative Innovation Center for Diagnosis and Treatment of Infectious Diseases, 79 Qingchun Street, Hangzhou 310003, China. ${ }^{5}$ Disease Prevention and Control Center of Henan Province, Zhengzhou 450016, China.
}

Received: 14 November 2017 Accepted: 1 November 2018

Published online: 15 November 2018

\section{References}

1. Wu Z, Sullivan SG, Wang Y, Rotheram-Borus MJ, Detels R. Evolution of China's response to HIV/AIDS. Lancet. 2007;369(9562):679-90.

2. Shen J, Yu DB. Governmental policies on HIV infection in China. Cell Res. 2005;15:903-7. https://doi.org/10.1038/sj.cr.7290366.

3. Chinese Center of Disease and Control. Chinese National Free AIDS Antiretroviral Therapy Manual, 2007.

4. Li H, Guo W, Li H, et al. Analysis of HIV-1 resistance in AIDS patients from a six-year cohort treated with antiviral therapy in a rural area in Henan Province. Chin J Med. 2011;21(91):1443-7.

5. Luo M, Liu H, Zhuang K, et al. Prevalence of drug-resistant HIV-1 in rural areas of Hubei Province in the People's Republic of China. Jaids-J Acq Imm Def. 2009;50(1):1-8.

6. Zhang M, Han XX, Cui WG, et al. The impacts of current antiretroviral therapy regimens on Chinese AIDS patients and their implications for HIV-1 drug resistance mutation. Jpn J Infect Dis. 2008;61(9):361-5.

7. Zhang $M, \operatorname{Han} X, \mathrm{Hu}$ Q, et al. Cohort study of highly active antiretroviral therapy and drug resistant mutation in Henan Province, China. Chin J Lab Med. 2008;31(10):1101-4.

8. Chinese Center of Disease and Control. Epidemic situation and the main prevention and control work progress of the national AIDS STD in May 2016. Chin J AIDS STD. 2016;(7):487.

9. Ning $\mathrm{H}$, Liang $\mathrm{H}$. Short-term efficacy of second-line antiretroviral therapy for AIDS patients. Shaanxi: Fourth National Conference of Chinese Medical Institute on AIDS, Viral Hepatitis C and tropical diseases; 2009.

10. Min QI, Guo-qiang Z, Wang L-j, Ke Z, Guo-tao L. Efficacy of second-line antiviral therapy for AIDS. J Clin Appl Med. 2011;6(6):40-1.

11. Zhang $M$, Shang M, Yang W, Chen J, Wang Z, Shang H. Treatment effect and drug-resistant mutations in chinese AIDS patients switching to secondline antiretroviral therapy. PLoS One. 2014;9(10):e110259.

12. Ding $\mathrm{H}$, Liu J, He Y, et al. Efficacy of long-term second-line antiretroviral therapy in HIV / AIDS patients in China. Chin J AIDS STD. 2017;09:776-9.

13. JianLiu YM, Zhang F. HIV antiretroviral therapy mode and the current situation in China. Chin J AIDS STD. 2012;18(10):711-4.

14. Fox MP, Ive $P$, Long L, Maskew M, Sanne I. High rates of survival, immune reconstitution, and virologic suppression on second-line antiretroviral therapy in South Africa. J Acquir Immune Defic Syndr. 2010;53(4):500-6.

15. Hosseinipour MC, Kumwenda JJ, Weigel R, et al. Second-line treatment in the Malawi antiretroviral programme: high early mortality, but good outcomes in survivors, despite extensive drug resistance at baseline. HIV Med. 2010;11(8):510-8. https://doi.org/10.1111/j.1468-1293.2010.00825.x.

16. Ferradini $L$, Ouk $V$, Segeral $O$, et al. High efficacy of lopinavir/r-based second-line antiretroviral treatment after 24 months of follow up at ESTHER/ Calmette Hospital in Phnom Penh, Cambodia. J Int AIDS Soc. 2011;14:14

17. Paton NI, Kityo C, Thompson J, Nankya I, Bagenda L, Hoppe A, Hakim J, Kambugu A, van Oosterhout JJ, Kiconco M, et al. Nucleoside reversetranscriptase inhibitor cross-resistance and outcomes from second-line antiretroviral therapy in the public health approach: an observational analysis within the randomised, open-label, EARNEST trial. Lancet HIV. 2017:4(8):E341-8.

18. Hakim JG, Thompson J, Kityo C, Hoppe A, Kambugu A, van Oosterhout JJ, Lugemwa A, Siika A, Mwebaze R, Mweemba A, et al. Lopinavir plus nucleoside reverse-transcriptase inhibitors, lopinavir plus raltegravir, or lopinavir monotherapy for second-line treatment of HIV (EARNEST): 144week follow-up results from a randomised controlled trial. Lancet Infect Dis. 2018;18(1):47-57.

19. Reynolds SJ, Laeyendecker O, Nakigozi G, et al. Antiretroviral drug susceptibility among HIV-infected adults failing antiretroviral therapy in Rakai, Uganda. AIDS Res Hum Retroviruses. 2012;28(12):1739-44.

20. Levison JH, Orrell C, Gallien S, et al. Virologic failure of protease inhibitorbased second-line antiretroviral therapy without resistance in a large HIV treatment program in South Africa. PLoS One. 2012;7(3):e32144.

21. Wallis $C L$, Mellors JW, Venter WD, et al. Protease inhibitor resistance is uncommon in HIV-1 subtype C infected patients on failing second-line Lopinavir/r-containing antiretroviral therapy in South Africa. AIDS Res Treat. 2011;2011:769627

22. Boyd MA, Moore CL, Molina J-M, Wood R, Madero JS, Wolff M, Ruxrungtham K, Losso M, Renjifo B, Teppler H, et al. Baseline HIV-1 
resistance, virological outcomes, and emergent resistance in the SECONDLINE trial: an exploratory analysis. Lancet HIV. 2015;2(2):E42-51.

23. Ajose O, Mookerjee S, Mills EJ, Boulle A, Ford N. Treatment outcomes of patients on second-line antiretroviral therapy in resource-limited settings: a systematic review and meta-analysis. Aids. 2012;26(8):929-38.

24. Chinese Center of Disease and Control. Chinese National Free AIDS Antiretroviral Therapy Manual, 2009.

25. World Health Organization. Rapid advice: Antiretroviral therapy for HIV infection in adults and adolescents. 2009, (https://www.ghdonline.org/ uploads/Rapid_Advice_Adult_ART_Guidelines_web.pdf).

26. Zhang M, Cui W, et al. Efficacy of anti-HIV treatment and drug-resistance mutations in some parts of China. Zhonghua Yi Xue Za Zhi. 2005;85(11):760-4.

27. Murphy RA, Sunpath $H$, Castilla C, et al. Second-line antiretroviral therapy: long-term outcomes in South Africa. J Acquir Immune Defic Syndr. 2012; 61(2):158-63.

28. HIV Drug Resistance Database. https:/hivdb.stanford.edu/dr-summary/ resistance-notes/NRTI/

29. Brenner BG, Coutsinos D. The K65R mutation in HIV-1 reverse transcriptase: genetic barriers, resistance profile and clinical implications. HIV Ther. 2009; 3(6):583-94.

30. Khan S, Das M, Andries A, et al. Second-line failure and first experience with thirdline antiretroviral therapy in Mumbai, India. Glob Health Action. 2014;7:1-6.

31. Sigaloff KCE, Hamers RL, Wallis $C L$, et al. Second-line antiretroviral treatment successfully Resuppresses drug-resistant HIV-1 after first-line failure: prospective cohort in sub-Saharan Africa. J Infect Dis. 2012;205(11):1739-44.

32. Ly JK, Margot NA, MacArthur HL, et al. The balance between NRTI discrimination and excision drives the susceptibility of HIV-1 RT mutants K65R, M184V and K65R+M184V. Antivir Chem Chemother. 2007;18(6):307-16.

Ready to submit your research? Choose BMC and benefit from:

- fast, convenient online submission

- thorough peer review by experienced researchers in your field

- rapid publication on acceptance

- support for research data, including large and complex data types

- gold Open Access which fosters wider collaboration and increased citations

- maximum visibility for your research: over $100 \mathrm{M}$ website views per year

At BMC, research is always in progress.

Learn more biomedcentral.com/submissions 